\title{
Produção de sementes \\ de essências nativas em floresta primária na Amazônia (1)
}

Luís M. S. Magalhães ( ${ }^{2}$ )

\begin{abstract}
Resumo
O autor descreve os trabalhos de seleção de árvores porta-sementes e coleta de sementes realizados no INPA-Manaus. Nesta seleção são consideradas as características de tipicidade, diâmetro à altura do peito, altura total, altura comercial, forma do fuste, forma da copa, posição da copa, e presença de sintomas de pragas e doenças. Relata que já existem marcadas cerca de setecentas árvores que servirão para futuros projetos de pesquisa de diversas espécies. O autor expõe também a metodologia empregada naquela área para coleta de frutos e sementes observando que dadas as características do povoamento esta coleta é feita, na grande maioria das essências, no solo, após dispersão. Ele discute ainda a aplicação da metodologia de seleção de porta-sementes em projetos de reflorestamento de essências nativas e recomenda a inclusão de exigências legais que regulem a implantação de áreas de coleta contíguas a projetos de exploração e reflorestamento.
\end{abstract}

\section{INTRODUÇÃO}

A medida que se avança no conhecimento de regiões de florestas tropicais úmidas, aumenta-se a certeza de que estes sistemas são bastante frágeis e altamente suscetíveis a intervenções drásticas. Dessa forma, existe hoje uma forte tendência, nos órgãos de planejamento agro-florestal da Amazônia brasileira, para utilizar-se a terra firme, através da implantação de sistemas que mais se assemelhem à floresta primária, criando condições para a manutenção dos fatores ecológicos envolvidos na renovação destes recursos. Nesse sentido, tem sido dada ênfase ao estudo de culturas perenes como frutíferas, laticíferas e essências madeireiras.

No que se refere à regeneração artificial de essências madeireiras, tem-se um número cada vez maior de projetos de reflorestamento com espécies nativas da Amazônia, tanto para cumprir a obrigação legal de reposição, após a exploração quanto para a obł̇enção de madeira de qualidades diferenciadas. Nestes projetos, um dos principais pontos de estrangulamento é o que se refere à difícil obtenção de sementes destas espécies, causada pela inexistência de áreas produtoras de sementes e pelas características da floresta primária. Entre outros problemas encontrados na produção de sementes da floresta primária, pode-se citar a grande diversidade de espécies e conseqüentemente a baixa freqüência de cada espécie por área, a dificuldade de acesso às árvores porta-sementes, a irregularidade na frutificação de algumas espécies e dificuldades na metodologia de coleta.

A acelerada exploração florestal em outras regiões do país levou à perda de importante material genético que hoje começa a fazer falta. A exploração seletiva de Jacarandá-da-Bahia (Dalbergia nigra), no sul da Bahia, praticamente exterminou os indivíduos de meIhores características fenotípicas, dificultando trabalhos de obtenção de sementes de boas matrizes. Assim, não se dispõe de material de propagação adequado, o que dificulta futuros trabalhos de melhoramento genético desta essência. Na Amazônia, ainda dispomos de uma imensa coleção primária que pode ser conservada. A manutenção de árvores porta-sementes, principalmente em áreas de exploração, deve ser feita no sentido de contar-se, no futuro, com o material genético acumulado nesta floresta.

A presente comunicação tem o objetivo de expor os trabalhos de seleção de porta-se-

\footnotetext{
(1) - Realizado com recursos do Banco Interamericano do Desenvolvimento e da Financiadora de Estudos e Projetos.

(2) - Instituto Nacional de Pesquisas da Amazônia, Manaus.
} 
mentes e coleta de sementes realizados no INPA, discutindo sua apiicação para o desenvolvimento silvicultural da Amazônia Brasileira.

\section{MATERIAL E MÉtodos}

\section{SELEÇÃO DE PORTA-SEMENTES}

Em circular técnica do Instituto de Pesquisas e Estudos Florestais, Kano et al. (1979), expondo a situação da produção de sementes florestais no Brasil, citam os diferentes tipos de áreas produtoras de sementes: 1) Áreas de Coleta de Sementes, onde as árvores são selecionadas e marcadas, sem haver eliminação de indivíduos inferiores. A seleção é realizada somente do lado feminino, já que não se controlam as árvores polinizadoras; 2) Areas de Produção de Sementes, que são instaladas a partir de povoamentos superiores, com eliminação das árvores inferiores e 3) Pomares de sementes, implantados a partir de árvores geneticamente superiores, isoladas, a partir de clones.

Dessa forma, partiu-se para uma metodologia prática que permitisse determinar as características de árvores de espécies nativas de interesse, visando à implantação de uma Área de Coleta de Sementes, na floresta primária, que servisse de ponto de partida para uma futura Area Produtora de Sementes em plantios controlados e propagados, a partir destes indivíduos selecionados na mata primária. Isto irá aumentar a probabilidade de contar-se com árvores de melhores características genéticas, facilitando futuros projetos de coleta de sementes.

Em trabalhos de seleção de matrizes de essências florestais, torna-se inviável o conhecimento das diferentes progênies que ocorrem em um povoamento. Desse modo, deve partir-se para uma metodologia prática que permita selecionar as árvores que tenham maiores probabilidades de boa carga genética. Pires (1979) descreve a seleção de árvores superiores de espécies exóticas, em plantios no Estado de São Paulo. O autor considera nesta seleção, inicialmente, a homogeneidade do sí- tio, já que dependendo de variações, nas condições ambientais, ocorreriam diferenças nas características fenotípicas em cada sítio, tendo que considerar-se diferentes padrões. A partir da delimitação de sítios homogêneos, o autor considera diversas características para a seleção dos indivíduos: Tipicidade da espécie, presença de sintomas de pragas e doenças e rabo-de-raposa (no caso de Pinus spp.) como eliminatórias; diâmetro à altura do peito (DAP), forma do fuste, altura, ângulo de inserção dos galhos, diâmetro dos galhos e derrama como características não eliminatórias. De todas estas características, apenas o DAP foi medido, com as outras características avaliadas subjetivamente por aquele autor.

Em floresta tropical úmida primária, a situação é bastante diversa da trabalhada por Pires (1979) e por tantos outros autores de regiões temperadas. Neste caso, o objetivo é de conservarem-se in situ, segundo a conceituação de Brune (1979), recursos genéticos em povoamentos primários, de diversas espécies de interesse silvicultural e econômico. Segundo Brune "se houver apenas populações comerciais selecionadas e especializadas, é bem provável que a base genética já seja muito estreita para fornecer uma variabilidade larga para o novo caráter em questão", sendo que "é neste ponto que as populações - base, com toda a variabilidade natural representada, se tornam importantes".

Partiu-se, então, para uma seleção de porta-sementes em uma floresta caracterizada por uma grande diversidade de espécies por área, uma baixa freqüência de indivíduos e para cada espécie a presença de árvores com diferentes idades. Assim, não foi considerada, a priori, a heterogeneidade do sítio. Outras características, como ângulo de inserção dos galhos, diâmetro dos galhos e derrama, foram também desprezados, tanto pelas dificuldades de avaliação no campo quanto pelo relativo desinteresse destas características, nesta fase de trabalho.

A área estudada fica na Reserva Florestal Ducke, no Km 26 da Rodovia Manaus-Itacoatiara e abrange cerca de $1 / 4$ da área total da Reserva que tem 10.000 hectares. Conforme Ro- 
drigues et al. (1971), a área está inserida no baixo - platô Amazônico, apresentando relevo que varia de plano a ondulado. A seleção de porta-sementes vem sendo realizada por uma equipe constituída de um mateiro e dois auxiliares de campo que percorrem a floresta de modo a atingir uma quadra pré.delimitada. Foi feita previamente uma lista de espécies desejáveis, que ocorrem naquela área e que consta no Projeto de Manejo e Exploração ex. perimental da floresta tropical úmida, elaborado pelo Departamento de Silvicultura do INPA (1979). A esta lista, foram acrescidas mais algumas espécies de interesse como Buchenavia sp e Ceiba sp, totalizando, no fim, sessenta espécies. Para cada árvore listada e com boas características fenotípicas, são registradas as seguintes informações:

1) Tipicidade - é feita uma identificação no campo $e$ é coletado material botânico para herborização e posterior identificação $\mathrm{cm}$ laboratório;

2) Diâmetro à altura do peito - determinado com auxílio de suta;

3) Alturas total $\in$ comercial - determinadas com auxílio de hipsomêtro Haga;

4) Forma do fuste;

5) Forma e posição da copa;

6) Presença de sintomas de pragas ou doenças.

A avaliação do item 4 foi, conforme a classificação de Shield (1965) citado por Alencar (1979). A avaliação do item 5 foi feita segundo a classificação que consta no Plano de Pesquisa Silvicultural de Uganda - PPSU (19561963) citado por Alencar (1979). Para cada árvore selecionada é pregada uma plaqueta de alumínio contendo o número de série correspondente, anotando-se a localização desta árvore na quadra correspondente. Nesta seleção de campo, foram consideradas árvores de boas características fenotípicas as que se apresentavam típicas da espécie, sem sintomas de pragas e doenças, com forma de fuste 4 ou 6, segundo Shield (1965), forma de Copa 4 ou 5 e Posição da Copa 4 ou 5 , segundo PPSU (1956-1963). Excluindo a tipicidade, as características consideradas foram avaliadas de forma menos exigente em casos de espécies de freqüência muito baixa.

A.pós o levantamento da área e dependendo do número de árvores selecionadas, no campo, de cada espécie, será feita nova seleção em escritório, escolhendo-se as árvores de melhores características para coletas de sementes. Esta nova seleção levará em conta além das características consideradas no campo, o DAP, a altura total e a altura comercial.

\section{COLETA DE SEMENTES}

A obtenção de sementes em florestas tropicais úmidas é bastante dificultada, entre outros motivos pelas dimensões das árvores que as compõe, pela dificuldade de acesso às matrizes, pela variação de estratégias de dispersão de frutos das diferentes espécies, pela baixa freqüência de cada espécie por área e pela alta predação de frutos e sementes por pássaros e roedores.

Como a grande parte das árvores que compõem estas florestas são muito altas (30-40 m) e de diâmetros de até 1,5 metros fica muito difícil o uso generalizado de equipamento para coleta em cima da árvore. A coleta de sementes na área de estudo é realizada principalmente após sua dispersão, no solo. Isto força uma atenção maior do coletor que deve conhecer, com relativa precisão, a época de queda dos frutos. Tornam-se, portanto, de grande utilidade o estudo fenológico das espécies que ocorrem na área, bem como o apoio de mateiros que conheçam através da cor dos frutos ou da presença de pássaros e roedores, a época adequada de coleta.

No quadro 1, apresentamos um esquema para coleta de sementes de algumas espécies nativas, construído a partir dos trabalhos de Alencar et al. (1979) e Sudam (1979).

Cada equipe de coleta, composta de um mateiro e um auxiliar rural equipados com binóculo, percorre as árvores das diferentes espécies que se encontram em período provável de frutificação, recolhendo os frutos que even- 
Anacardium giganteum *

Anacardium spruceanum *

Andira unifoliolata*

Aniba duckei* *

Aspidosperma album"*

Astronium lecointei" *

Bagassa guyanensis *

Calophyllum angulare*

Carapa guyanensis *

Cariniana micrantha"

Caryocar villosum *

Cedrela odorata* *

Cedrelinga catenaeformis *

Ceiba pentandra* "

Clarisia racemosa "

Copaifera multijuga

Cordia goeldiana ${ }^{*}$

Couma macrocarpa

Dinizia excelsa

Dipteryx odorata

Didymopanax morototoni *

Euxylophora paraensis *

Goupia glabra*

Hura crepitans *

Hymenaea courbaril *

Hymenolobium petraeum ${ }^{* *}$

Jacaranda copaia"

Lecythis usitata"

Manilkara huberi" "

Manilkara surinamensis *

Mezilaurus itaúba *

Mezilaurus synandra*

Nectandra rubra*

Osteophoeum platyspermum *

Peltogyne catingae*

Pithecolobium racemosum

Platymiscium duckei ${ }^{*}$

Platymiscium trinitatis *

Scleronema micranthum *

Simaruba amara *

Swietenia macrophylla*

Tabebuia incana*

Tabebuia serratifolia* *

Virola michelii"

Virola surinamensis *

Vochysia maxima*

Vouacapua americana* *

Voucapoua pollidior"
Caju-açu

Cajuí

Sucupira chorona

Pau-rosa

Araracanga

Muiracatiara

Tatajuba

Jacareúba

Andiroba

Castanha-de-macaco

Piquiá

Cedro

Cedrorana

Sumaúma

Guariúba

Copaíba

Freijó

Sorva grande

Angelim pedra

Cumaru

Morototó

Pau-amarelo

Cupiúba

Açacu

Jutaí-açu

Angelim da mata

Caroba

Castanha-sapucaia

Maçaranduba

Maçaranduba

Itaúba

Itaúba-folha-fina

Louro gamela

Ucuúba branca

Violeta

Angelim rajado

Macacaúba

Macacaúba

Cardeiro

Marupá

Mogno

Pau d'arco

Pau d'arco

Ucuuba preta

Ucuuba

Quaruba

Acapu

Acapu
Outubro a novembro

Setembro a dezembro Junho a dezembro

Dezembro a junho

Janeiro a fevereiro

Agosto a setembro

Junho a agosto

Junho a dezembro

Março a maio

Janeiro a agosto

Março a maio

Outubro a novembro

Janeiro a maio

Setembro a outubro

Fevereiro a março

Março a agosto

Janeiro a março

Outubro a abril

Setembro a dezembro

Março a agosto

Outubro a novembro

Outubro a novembro

Junho a outubro

Junho a julho

Março a julho

Maio a junho

Setembro a dezembro

Junho a agosto

Dezembro a fevereiro

Setembro a fevereiro

Junho a agosto

Agosto a dezembro

Setembro a dezembro

Outubro a abril

Outubro a abril

Setembro a fevereiro

Setembro a dezembro

Abril a maio

Setembro a fevereiro

Novembro a dezembro

Outubro a novembro

Setembro a dezembro

Outubro a novembro

Setembro a dezembro

Junho a agosto

Março a abril

Outubro a novembro

Janeiro a maio

Fontes: * Alencar, 1979 - Manaus-AM

* SUDAM (1979) - Curuá-Una-PA 
tualmente tenham caído de cada árvore. Para cada árvore coletada, são anotadas em planiIha as informações pertinentes, como localização da porta-sementes, data, método de coleta e nome vulgar da espécie coletada.

\section{RESULTADOS JÁ OBTIDOS}

Para a composição da Área de Coleta de Sementes da Reserva Ducke, já estão sendo utilizadas 500 árvores marcadas e que fazem parte do Estudo Fenológico implantado no ano de 1965 e com resultados parciais publicados por Alencar et al. (1979). Além destas, cerca de 200 árvores novas foram mapeadas. 0 rendimento da equipe de campo foi de 8 árvores selecionadas por dia, em média. Este número foi determinado a partir do número médio de árvores selecionadas em quatro dias de trabaIho ininterruptos, considerando uma lista de 60 espécies.

Nas operações de coleta, foram obtidas sementes de 34 espécies no período de janeiro a junho de 1981. O rendimento de cada equipe foi de cerca de 4.700 sementes por mês, determinado a partir do total de sementes produzidas durante seis meses dividido pelo número de meses.

\section{Discussão}

O aumento na demanda de sementes de espécies florestais nativas da Amazônia e a crescente exploração do potencial genético da floresta primária naquela região reforçam, cada vez mais, a necessidade de implantarem-se áreas de coleta de sementes, de modo a fornecer material para reflorestamento e manter a variabilidade genética natural existente nestes povoamentos. Brune (1979) afirma que em se tratando de população "in situ", isto é, "povoamentos naturais normalmente em conjunto com outras espécies da flora e da fauna" o adequado seria "manter representações de populaçø̋es em diversos locais de ocorrência natural". Dubois (1971) também manifesta esta preocupação, fazendo referências à acelerada exploração do Mogno (Swietenia macrophyla) em algumas localidades da Amazônia e recomendando a criação de reservas para proteção daquela espécie em zonas de maior extração.

Assim, além das Reservas Biológicas, Parques, Santuários e outras áreas de preservação permanente, deve-se desde já partir para a aplicação de medidas que garantam a manutenção deste material no futuro. Neste sentido, deve-se criar e aplicar mecanismos legais que garantam a formação da área de coleta de sementes em áreas contíguas aos projetos de exploração e reflorestamento na Amazônia. Estas áreas produtoras garantiriam o fornecimento de material de propagação para reflorestamento e serviriam como base genética para futuros projetos de melhoramento.

A metodologia empregada para seleção de porta-sementes aqui descrita tem-se mostrado exeqüivel e adequada para fins de pesquisa como estudos de produção de sementes, estudos de características culturais de sementes e seleção de material genético visando melhoramento. No entanto, em se tratando de florestas tropicais úmidas, como é o caso da Amazônia, esta metodologia poderá ser modificada, segundo o objetivo principal de cada projeto. No caso de seleção de porta-sementes visando fornecimento para plantios, pode-se fazer uma avaliação de cada árvore de forma mais subjetiva, eliminando-se medições de altura e diâmetro da copa. Isto daria um maior rendimento tornando o projeto mais accessível.

A manutenção de duas equipes de coleta, durante 6 meses, resultou na produção de 56.400 sementes, em um ano considerado de baixa produção pelos mateiros da região. Mantendo-se este ritmo, poder-se-ia produzir cerca de 100.000 sementes durante este período, o que seria suficiente para reflorestar uma área razoável. Assim, a implantação de Áreas de Coleta de Sementes e a manutenção de equipes de coleta em cada projeto de exploração-reflorestamento de essências nativas na Amazônia, poderá contribuir, de forma decisiva, para o desenvolvimento silvicultural da região. 


\section{CONCLUSÕES E RECOMENDAÇões}

1) A metodologia utilizada para seleção de árvores porta-sementes tem se mostrado exeqüível e adequada às condições amazônicas;

2) $O$ rendimento obtido na seleção de porta-sementes e na coleta de sementes foi considerado bom, podendo aumentar em função dos objetivos de futuros projetos;

3) Medidas devem ser tomadas no sentido de preservar-se o patrimônio genético das florestas primárias da Amazônia, incluindo-se nas exigências para aprovação de projetos de exploração e reflorestamento, a de implantação de áreas de coleta de sementes visando não só à manutenção do patrimônio genético como ao suprimento de sementes para os projetos.

\section{AgRADECIMENTOS}

O autor agradece aos funcionários Vicente Faustinc do Nascimerito e Jorge das Chagas Duarte pelos trabalhos desenvolvidos no campo. Agradece também ao Departamento de Botânica do INPA, na pessoa do Dr. William Rodrigues pela identificáção do material botânico, bem como ao pesquisador Jurandyr da Cruz Alencar pelas sugestões apresentadas e Valdecira J. Azevedo pelo datilografamento do texto.

\section{SUMMARY}

The author describes work on seed bearing tree selection and seed collection realized at INPA-Manaus. In this selection the following characteristics were considered: tipicity, DBH, total height, commercial height, stem shape, crown shape, crown position and disease symptoms. The existence of about seven hundred trees of several species that will be useful in future research projects are reported. The metodology of fruit and seed collection in the experimental area is described. The author notes that because of the characteristics of the population seed collection was made on the ground, after dispersion, for most of the species. He also discusses the metodological aplication of seed bearer selection in reforestation projects of native species and recommends the inclusion of legal regulations for the implantation of collection areas side by side with exploitation and reforestation projects.

\section{REFERENCIAS BIBLIOGRAFICAS}

ALENCAR, J.C.; ALMEIDA, R.A. \& FERNANDES, N.P. 1979 - Fenologia de espécies florestais em floresta tropical úmida de terra firme da Amazônia Central. Acta Amazonica, 9 (1): 163198.

BRUNE, A

1979 - Populações Genéticas - Base - Conceitos e Considerações. Sociedade de Investigações Florestais. Boletim Técnico (Especial) 2: 147-151.

DUBOIS, J.L.C.

1971 - Silvicultural Research in the Amazon. FO: SF/BRA 4. Technical Report FAO (3).

INPA. DEPARTAMENTO DE SILVICULTURA

1979 - Projeto de Manejo e Exploração Experimental de Floresta Tropical Úmida INPA-CNPq. Manaus.

KANO, N.K.; GONÇALVES, J.C.; KAGEYAMA, P.Y.; \& JACOB, W.S.

1979 - Situação da Produção de Sementes Florestais no Brasil. Instituto de Pesquisas e Estudos Florestais. Circular Técnica (48).

PIRES, C.L. da Silva

1979 - Seleção de Arvores Superiores. Public. I.F., São Paulo, 20: 1-12.

RODRIGUES, T.E.; MORIKAWA, I.K.; REIS, R.S. dos; FALESI, I.C.

1971 - Solos do Distrito Agropecuário da SUFRA. MA. I.P.E.A.A.O.C. Manaus.

SUDAM - DEPARTAMENTO DE RECURSOS NATURAIS CENTRO DE TECNOLOGIA MADEIREIRA

1979 - Pesquisas e Informações sobre Espécies Florestais da Amazônia, Belém, 111 págs. ilust. 